\title{
Anti-Fas Gene Therapy Prevents Doxorubicin-Induced Acute Cardiotoxicity through Mechanisms Independent of Apoptosis
}

\author{
Shusaku Miyata, ${ }^{*}$ Genzou Takemura, ${ }^{*}$ \\ Ken-ichiro Kosai, ${ }^{\dagger}$ Tomoyuki Takahashi, ${ }^{\ddagger}$ \\ Masayasu Esaki, ${ }^{*}$ Longhu Li, ${ }^{*}$ \\ Hiromitsu Kanamori, ${ }^{*}$ Rumi Maruyama, ${ }^{*}$ \\ Kazuko Goto, * Akiko Tsujimoto, ${ }^{*}$ \\ Toshiaki Takeyama, ${ }^{*}$ Tomonori Kawaguchi, ${ }^{*}$ \\ Takamasa Ohno, ${ }^{\S}$ Kazuhiko Nishigaki, ${ }^{*}$ \\ Takako Fujiwara, ${ }^{\text {Tा }}$ Hisayoshi Fujiwara, ${ }^{*}$ \\ and Shinya Minatoguchi*

\begin{abstract}
From the Division of Cardiology,* Gifu University Graduate School of Medicine, Gifu; the Department of Gene Therapy and Regenerative Medicine, ${ }^{\dagger}$ Kagoshima University Graduate School of Medicine and Dental Sciences, Kagoshima; the Division of Gene Therapy and Regenerative Medicine, ${ }^{\ddagger}$ Cognitive and Molecular Research Institute of Brain Diseases, Kurume University, Kurume; the Laboratory of Medical Resources, ${ }^{\S}$ School of Pharmacy, Aichi Gakuin University, Nagoya; and the Department of Food Science, "T Kyoto Women's University, Kyoto, Japan
\end{abstract}

Activation of Fas signaling is a key mediator of doxorubicin cardiotoxicity, which involves both cardiomyocyte apoptosis and myocardial inflammation. In this study, acute cardiotoxicity was induced in mice by doxorubicin, and some mice simultaneously received an intramuscular injection of adenoviral vector encoding mouse soluble Fas (sFas) gene (Ad.CAG-sFas), an inhibitor of Fas/Fas ligand interaction. Two weeks later, left ventricular dilatation and dysfunction were apparent in the LacZ-treated control group, but both were significantly mitigated in the sFas-treated group. The $i n$ situ nick-end labeling-positive rate were similar in the two groups, and although electron microscopy revealed cardiomyocyte degeneration, no apoptotic structural features and no activation of caspases were detected, suggesting an insignificant role of apoptosis in this model. Instead, sFas treatment reversed doxorubicininduced down-regulation of GATA- 4 and attenuated ubiquitination of myosin heavy chain and troponin I to preserve these sarcomeric proteins. In addition, doxorubicin-induced significant leukocyte infiltration, fibrosis, and oxidative damage to the myocardium, all of which were largely reversed by sFas treatment. sFas treatment also suppressed doxorubicin-induced p53 overexpression, phosphorylation of c-Jun $\mathbf{N}$-terminal kinase, $c-J u n$, and inhibitor of nuclear factor- $\kappa \mathrm{B}$, as well as production of cyclooxygenase- 2 and monocyte chemoattractant protein-1, and it restored extracellular signal-regulated kinase activation. Therefore, sFas gene therapy prevents the progression of doxorubicininduced acute cardiotoxicity, with accompanying attenuation of the cardiomyocyte degeneration, inflammation, fibrosis, and oxidative damage caused by Fas signaling. (Am J Pathol 2010, 176:687-698; DOI: 10.2353/ajpath.2010.090222)

The antineoplastic drug doxorubicin (adriamycin) is effective in the treatment of a broad range of hematogenous and solid human malignancies, but its clinical use is limited by its dose-dependent side effects: irreversible degenerative cardiomyopathy and congestive heart failure. ${ }^{1-3}$ The efficacy of doxorubicin against cancer has prompted a search to find treatments that reduce or prevent its cardiac side effects. ${ }^{3,4}$ So far, however, the ability of these treatments to protect the heart from doxorubicin has been varied and limited.

The interaction of Fas with Fas ligand is an important trigger for apoptosis in many cell types, particularly cells related to the immune system. ${ }^{5}$ Moreover, it has recently come to light that the Fas/Fas ligand interaction plays an important role in the development and progression of doxorubicin cardiomyopathy. Nakamura et al showed that in a rat doxorubicin cardiomyopathy model, myocardial Fas expression and cardiomyocyte apoptosis were concomitantly increased and that a neutralizing antibody against Fas ligand attenuated both, leading to improvement in cardiac function. ${ }^{6}$ In addition, Yamaoka et al

Supported in part by grants-in-aid for scientific research 15209027 , 15590732, 14570700, and 13470143 from the Ministry of Education, Science and Culture of Japan.

Accepted for publication October 21, 2009.

Address reprint requests to Genzou Takemura, M.D., Ph.D., Division of Cardiology, Gifu University Graduate School of Medicine, 1-1 Yanagido, Gifu 501-1194, Japan. E-mail: gt@gifu-u.ac.jp. 
showed that Fas/Fas ligand interaction increases the susceptibility of cultured neonatal cardiomyocytes to doxorubicin-induced apoptosis. ${ }^{7}$ Conversely, treatment with doxorubicin up-regulates expression of both Fas ligand and Fas in various organs, including the heart. ${ }^{6,8}$ On the other hand, cardiomyocytes are reportedly very insensitive to Fas stimulation, ${ }^{9,10}$ and one recent study reported that doxorubicin-induced cardiomyocyte apoptosis is independent of Fas signaling. ${ }^{11}$ It is noteworthy in that regard that there is as yet no in vivo morphological evidence of the involvement of cardiomyocyte apoptosis in doxorubicin cardiotoxicity, despite numerous biochemical findings indicative of apoptosis (eg, DNA fragmentation, caspase activation). ${ }^{12,13}$ In fact, we and others have never detected apoptotic cardiomyocytes in some in vivo models of doxorubicin cardiotoxicity. ${ }^{14,15}$ Thus, the role of Fas-dependent cardiomyocyte apoptosis, or any other form of apoptosis, remains controversial in the pathogenesis of doxorubicin cardiotoxicity.

Recent studies indicate that Fas signaling also exerts biological effects unrelated to apoptosis, such as induction of inflammation and fibrosis, ${ }^{16}$ generation of reactive oxygen species, ${ }^{17}$ acceleration of proliferation/differentiation, ${ }^{18}$ and induction of hypertrophy. ${ }^{19}$ Indeed, its proinflammatory and hypertrophic effects have been noted in both heart and cardiomyocytes. ${ }^{19,20}$ We therefore hypothesized that Fas signaling might contribute to the pathogenesis of doxorubicin cardiotoxicity through mechanisms unrelated to induction of cardiomyocyte apoptosis. To test that idea, we examined the efficacy of gene therapy using an adenoviral vector expressing soluble Fas (sFas), an inhibitor of Fas/Fas ligand interaction, on cardiac function and morphology in our mouse model of doxorubicin-induced acute cardiotoxicity where the role of apoptosis seems insignificant ${ }^{15}$ and investigated the specific mechanisms involved in the observed effects.

\section{Materials and Methods}

\section{Recombinant Adenoviral Vectors}

A replication-incompetent adenoviral vector that ubiquitously and strongly expresses a chimeric fusion protein comprised of the extracellular region of mouse Fas and the $F c$ region of human $\lg _{1}$ ( $m F a s-F c$ ), ie, soluble Fas (sFas), was generated as follows. The adenoviral vector plasmid pAd-sFas, which includes the cytomegalovirus immediate early enhancer, a modified chicken $\beta$-actin promoter, rabbit $\beta$-globin polyA (CAG), and sFas cDNA (Ad.CAG-sFas) was constructed using in vitro ligation as described previously. ${ }^{21}$ Plasmid pFAS-Fcll was generously provided by Dr. S. Nagata (Osaka University Graduate School of Medicine). ${ }^{22}$ Control Ad-LacZ (Ad.CAGLacZ) was prepared as described previously. ${ }^{23}$

\section{Experimental Protocols}

This study was approved by our Institutional Animal Research Committee. Cardiotoxicity was induced in 10week-old male C57BL/6J mice (Japan SLC) with a single intraperitoneal injection of doxorubicin hydrochloride (Kyowa Hakko) at a dose of $15 \mathrm{mg} / \mathrm{kg}$ in saline $(n=20)$.

Just after the injection of doxorubicin, the sFas gene or LacZ gene was systemically delivered to mice by injection of Ad.CAG-sFas or Ad.CAG-LacZ $\left(1 \times 10^{9} \mathrm{pfu} /\right.$ mouse) into the hindlimb muscles ( $n=10$ each). In shamtreated mice $(n=18)$, the same volume of saline $(n=10)$ or Ad.CAG-sFas $(n=8)$ was injected in a similar manner.

\section{Measurement of the sFas Level in Plasma}

The plasma concentration of sFas was measured 1 and 2 weeks after injection of Ad.CAG-sFas or Ad.CAG-LacZ ( $n=3$ each) by detecting human IgG-Fc using an enzyme-linked immunosorbent assay kit (Institute of Immunology) as previously reported. ${ }^{24}$

\section{Physiological Studies}

Physiological studies (echocardiography and cardiac catheterization) were performed as described previously with modifications. ${ }^{15}$ Animals were anesthetized with halothane (induction, $2 \%$; maintenance, $0.5 \%$ ) in a mixture of $\mathrm{N}_{2} \mathrm{O}$ and $\mathrm{O}_{2}(0.5 \mathrm{l} / \mathrm{min}$ each) via a nasal mask. Echocardiograms were recorded before treatment and at sacrifice using an echocardiographic system (Vevo 770; VisualSonics) equipped with a $45-\mathrm{MHz}$ imaging transducer. Following echocardiography, the right carotid artery was cannulated with a micromanometer-tipped catheter (SPR 671; Millar Instruments) that was advanced into the aorta and then into the left ventricle (LV) to record pressure and maximal and minimal $\mathrm{dP} / \mathrm{dt}( \pm \mathrm{dP} / \mathrm{dt})$.

\section{Histological Analysis}

Once the physiological measurements were complete, all mice were sacrificed, and the hearts were removed. Randomly chosen six hearts from each group served for histological analyses. The heart was cut in two by making a transverse slice between the atrioventricular groove and the apex. The basal specimens were fixed in 10\% buffered formalin, embedded in paraffin, cut into $4-\mu \mathrm{m}$ thick sections and stained with hematoxylin and eosin, Masson's trichrome and Sirius red F3BA ( $0.1 \%$ solution in saturated aqueous picric acid, Sigma-Aldrich). Quantitative assessments, including fibrosis area, cardiomyocyte size, and immunopositive cell number, were performed in 20 randomly chosen high power fields (HPFs, $\times 400$ ) in each section using a multipurpose color image processor (LUZEX F, Nireco). The cardiomyocyte size was expressed as the transverse diameter of myocytes cut at the level of the nucleus.

\section{Immunohistochemistry}

After deparaffinization, the 4- $\mu$ m-thick sections were incubated with a primary antibody against panleukocyte antigen (CD45; PharMingen), guanine derivative 8-hydroxy-2'-deoxyguanosine (8-OHdG; Japan Institute of 
The Control of Aging), or 4-hydroxyl-2-nonenal (4-HNE; NOF corporation). A Vectastain Elite ABC system (Vector Laboratories) was then used to immunostain the sections; diaminobenzidine served as the chromogen, and the nuclei were counterstained with hematoxylin.

\section{In Situ Nick End-Labeling (TUNEL) and DNA Gel Electrophoresis}

TUNEL assays were performed with sections using an ApopTag kit (Intergene) principally according to the supplier's instruction. Mammary tissue from the mice served as a positive control. In addition, to evaluate apoptosis of cardiomyocytes, we performed double immunofluorescence for myoglobin combined with TUNEL. Tissue sections were first stained with Fluorescein-FragEL (Oncogene) and then labeled with antimyoglobin antibody (DAKO) followed by Alexa 568 . Nuclei were stained with Hoechst 33342. Immunofluorescence preparations were observed under a confocal microscope (LSM510, Zeiss). Extraction of DNA from apical halves of cardiac tissue $(n=3$ each per group) and its subsequent electrophoresis were performed as described previously. ${ }^{25}$

\section{Electron Microscopy}

Apical halves of the hearts ( $n=3$ from each group) were minced and fixed in phosphate-buffered 2.5\% glutaraldehyde solution ( $\mathrm{pH}$ 7.4) overnight, postfixed with $1 \%$ osmium tetroxide for 1 hour, dehydrated through a graded ethanol series and embedded in Epon medium. Ultrathin sections were stained with uranyl acetate and lead citrate and observed in an electron microscope (H700; Hitachi).

We performed a morphometric analysis under an electron microscope using the method previously described. ${ }^{26}$ A uniform sampling of 20 electron micrographs, 10 with myofibrils oriented longitudinally and 10 with myofibrils sectioned transversely, was used for the morphometric assay of each group. Five random fields, micrographed at $10,000 \times$ from each of five tissue blocks were printed at a final magnification of $30,000 \times$ and analyzed on composite grids as described previously, to calculate the volume fraction of myofibrils and mitochondria within a cardiomyocyte.

\section{Western Blotting}

Samples of protein $(100 \mu \mathrm{g})$ extracted from hearts $(n=4$ from each group) were subjected to $14 \%$ polyacrylamide gel electrophoresis and then transferred onto polyvinylidene difluoride membranes. The membranes were then probed using primary antibodies against Fas, Fas ligand (both from BD Transduction Laboratories/BD PharMingen), caspase-8, caspase-3 (both from Cell Signaling, Danvers, MA), Bcl-2, Bax (both from Santa Cruz), extracellular signal-regulated kinase (ERK), the phosphorylated (activated) form of ERK ( $p$-ERK; both from Cell Signaling),
c-Jun N-terminal kinase (JNK), the phosphorylated form of JNK (p-JNK; both from Santa Cruz), p38 mitogenactivated protein kinase (p38 MAPK), the phosphorylated form of p38 MAPK (p-p38; both from Sigma-Aldrich), $c-J u n$, the phosphorylated form of c-Jun ( $p$-Jun; both from Cell Signaling), inhibitor of nuclear factor- $\kappa \mathrm{B}\left(\mathrm{I}_{\kappa} \mathrm{B}\right)$, the phosphorylated form of $\left.\right|_{\kappa} \mathrm{B}\left(\mathrm{p}-\mathrm{I}_{\kappa} \mathrm{B}\right.$; both from Cell Signaling), GATA-4, myosin heavy chain (MHC), troponin I, p53, cyclooxygenase-2 (COX-2), monocyte chemoattractant protein-1 (MCP-1; all from Santa Cruz), transforming growth factor- $\beta 1$ (TGF- $\beta 1$; Promega) and $4-\mathrm{HNE}$ (NOF Corporation), after which the blots were visualized using enhanced chemiluminescence (ECL; GE HealthCare UK Ltd.). $\alpha$-Tubulin (antibody from Santa Cruz) served as the loading control.

\section{Ubiquitination Assay Using Immunoprecipitation}

An immunoprecipitation assay of the lysate of heart tissues was performed using anti-MHC or anti-troponin I antibody (Santa Cruz) with Dynabeads/protein A (Dynal; Invitrogen) according to the supplier's instruction. Subsequently, the isolated protein was analyzed by Western blotting using anti-ubiquitin antibody (Dako). Three hearts from each group were subjected to the assay.

\section{Enzyme-Linked Immunosorbent Assay}

The level of tumor necrosis factor- $\alpha$ (TNF- $\alpha$ ) in myocardial tissue ( $n=4$ from each group) was quantified using enzyme-linked immunosorbent assay kits (R\&D Systems) according to the supplier's instructions.

\section{Statistical Analysis}

Values are shown as means \pm SEM The significance of differences between groups was evaluated using oneway analysis of variance with a post hoc Newman-Keuls multiple comparisons test. Values of $P<0.05$ were considered significant.

\section{Results}

\section{Effects of sFas on Doxorubicin-Induced Changes in Cardiac Structure and Function}

In the sFas gene-delivered mice, the plasma level of exogenous sFas reached $76 \pm 8.0 \mu \mathrm{g} / \mathrm{ml} 1$ week after injection. It steeply decreased to $3.2 \pm 0.18 \mu \mathrm{g} / \mathrm{ml} 2$ weeks after injection when the experiments ended; these levels might be sufficiently high when considering that in humans, the normal level of plasma sFas is approximately 2 $\mathrm{ng} / \mathrm{ml} .{ }^{27}$ Exogenous sFas was not detected in the plasma of mice that received LacZ gene at any time point.

Two weeks after doxorubicin administration, all of the mice of each group remained alive. Echocardiography and cardiac catheterization performed at that time showed that mice receiving doxorubicin and LacZ gene 


\section{A}
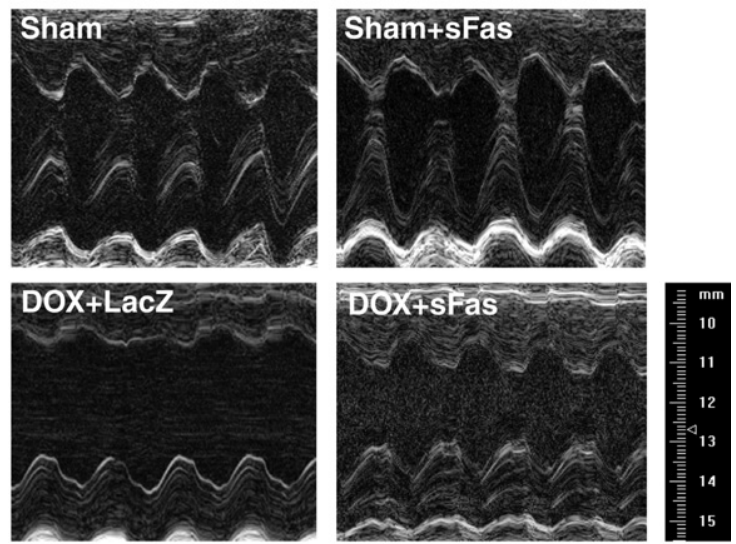

B
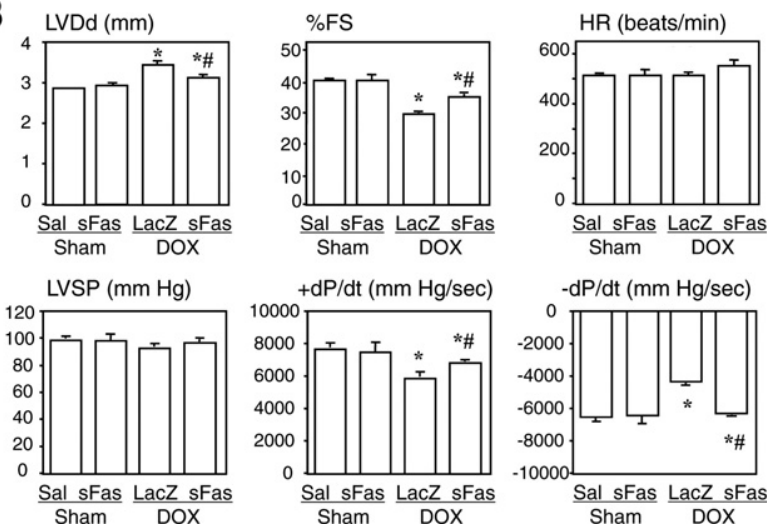

Figure 1. Effects of sFas gene delivery on LV geometry and function evaluated with echocardiography and cardiac catheterization 2 weeks after doxorubicin injection. A: Representative M-mode echocardiograms at the level of the ventricles in each group. B: Comparison of hemodynamic parameters among the groups. LVDd, left ventricular end-diastolic dimension; \%FS, \%fractional shortening; LVSP, left ventricular peak systolic pressure. Sal, saline treatment; sFas, sFas gene transfer; LacZ, LacZ gene transfer; DOX, doxorubicin treatment. ${ }^{*} P<0.05$ versus the salinetreated sham group; ${ }^{\#} P<0.05$ versus the doxorubicin-treated group with LacZ gene transfer.

had substantial deterioration of cardiac function characterized by enlargement of the LV cavity, increased LV diameter, reduced LV fractional shortening and reduced $\pm \mathrm{dP} / \mathrm{dt}$, as compared with sham animals (Figure 1, A and B). Treatment with sFas gene significantly attenuated the doxorubicin-induced impairment of cardiac function but showed no influence on cardiac geometry and function in the sham-treated mice.

We observed no significant difference in the heart weight-to-body weight ratios among the groups (Table 1). On the other hand, examination of transverse sections of hearts stained with hematoxylin-eosin showed that cardiomyocytes were severely degenerative from the group receiving doxorubicin plus LacZ; they contained many vacuoles and the sarcomeres were poorly stained with eosin (Figure 2A). The transverse diameters of cardiomyocytes from this group were significantly smaller than in the sham group. The sFas treatment improved the doxorubicin-induced degenerative findings in cardiomyocytes (Figure 2A) but exerted no effect against this apparent cardiomyocyte atrophy (Table 1).
Table 1. Morphometric Data from Hearts

\begin{tabular}{|c|c|c|c|}
\hline & $\begin{array}{l}\text { Sham } \\
(n=10)\end{array}$ & $\begin{array}{c}\text { DOX + } \\
\text { LacZ } \\
(n=10)\end{array}$ & $\begin{array}{c}\mathrm{DOX}+\mathrm{sFas} \\
(n=10)\end{array}$ \\
\hline $\begin{array}{l}\text { Heart weight } \\
(\mathrm{mg})\end{array}$ & $95 \pm 2.1$ & $81 \pm 4.3^{*}$ & $83 \pm 3.1^{*}$ \\
\hline $\begin{array}{l}\text { Body weight }(\mathrm{g}) \\
\text { Heart to body } \\
\text { weight ratio } \\
(\mathrm{mg} / \mathrm{g})\end{array}$ & $\begin{array}{c}26 \pm 0.4 \\
3.7 \pm 0.06\end{array}$ & $\begin{array}{l}23 \pm 0.7^{*} \\
3.6 \pm 0.13\end{array}$ & $\begin{array}{c}22 \pm 0.7^{*} \\
3.7 \pm 0.17\end{array}$ \\
\hline $\begin{array}{l}\text { Size of myocyte } \\
(\mu \mathrm{m})\end{array}$ & $14.0 \pm 0.2$ & $12.3 \pm 0.1^{*}$ & $12.6 \pm 0.3^{\star}$ \\
\hline $\begin{array}{l}\mathrm{CD}^{2} 5^{+} \text {cells } \\
\text { (/HPF) }\end{array}$ & $4.4 \pm 0.28$ & $7.6 \pm 0.41^{*}$ & $4.8 \pm 0.34^{\star \dagger}$ \\
\hline$\%$ fibrosis & $0.46 \pm 0.02$ & $1.04 \pm 0.07^{*}$ & $0.73 \pm 0.06^{* \dagger}$ \\
\hline $\begin{array}{l}\text { 8-OHdG }{ }^{+} \text {cells } \\
\text { (/HPF) }\end{array}$ & $1.5 \pm 0.1$ & $16 \pm 0.2^{*}$ & $4.5 \pm 0.1^{\star \dagger}$ \\
\hline
\end{tabular}

\section{Effects of sFas on Doxorubicin-Induced Inflammatory Responses, Fibrosis, and Oxidative Damage}

Immunohistochemical analysis revealed that doxorubicin induced significant infiltration of the myocardium by CD45-positive leukocytes (Figure 2A) and that sFas attenuated this effect, significantly reducing doxorubicininduced CD45-positive leukocyte infiltration (Table 1). When we assessed cardiac fibrosis using Sirius redstained sections (Figure 2A), we found that the amount of fibrosis was significantly greater in the group receiving doxorubicin plus LacZ than in the sham group, and that this effect, too, was significantly reduced by sFas treatment (Table 1). The $8-\mathrm{OHdG}$ is a commonly used marker of oxidative damage to DNA. ${ }^{28}$ We found that the prevalence of 8-OHdG-positive cardiomyocytes was markedly increased in the group receiving doxorubicin plus LacZ and that such oxidative damage was markedly attenuated in the sFas-treated mice (Figure 2A and Table 1). 4-HNE, a marker of oxidative damage to cell membranes, ${ }^{29}$ is an $\alpha, \beta$-unsaturated aldehyde that can be formed by peroxidation of $\omega 6$-unsaturated fatty acids such as linoleic and arachidonic acids. ${ }^{30}$ It has been proposed that 4-HNE exerts a variety of cytotoxic, genotoxic, and mutagenic effects as well as inhibitory effects on cell proliferation because its facile reactivity with biological molecules, particularly with proteins. We similarly noted strong immunolabeling of 4-HNE in the hearts of doxorubicin-treated mice, and the labeling was substantially weaker in mice receiving the sFas gene therapy (Figure 2A). This finding was subsequently confirmed by Western blotting of 4-HNE (Figure 2B).

Western blot analyses revealed up-regulation of two inflammatory mediators cyclooxygenase-2 and MCP- 1 in the doxorubicin-treated hearts, which was reversed by the sFas gene therapy (Figure 3A). On the other hand, tissue levels of TGF- $\beta 1$ and TNF- $\alpha$ were unaffected by doxorubicin (Figure $3, \mathrm{~A}$ and $\mathrm{B}$ ). 
A

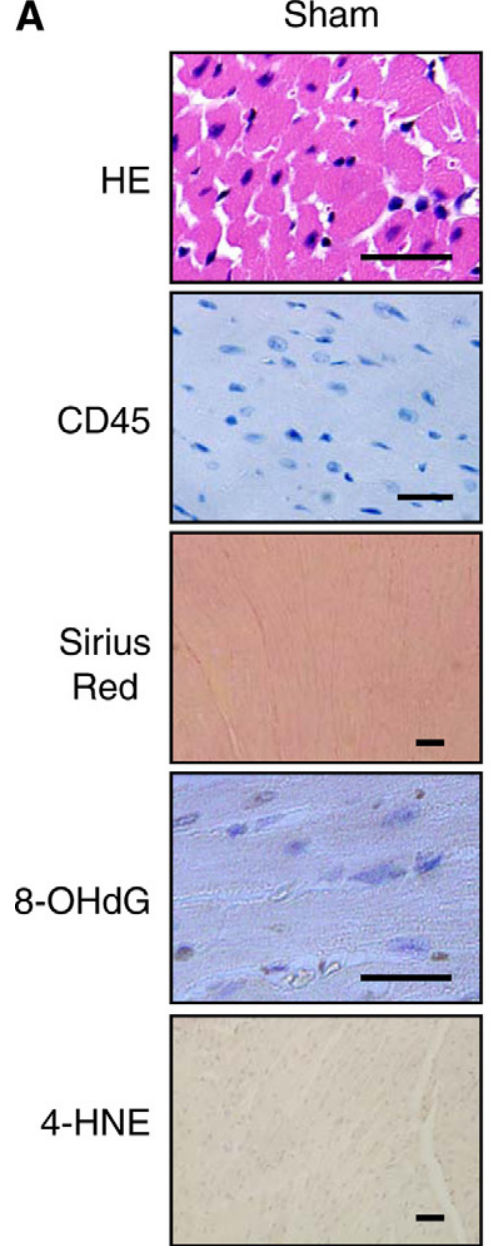

DOX+LacZ
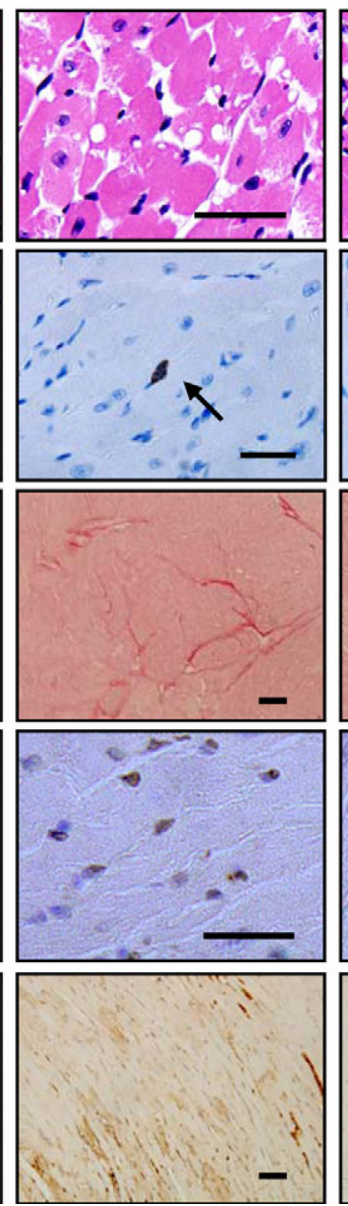

$\mathrm{DOX}+\mathrm{SFas}$

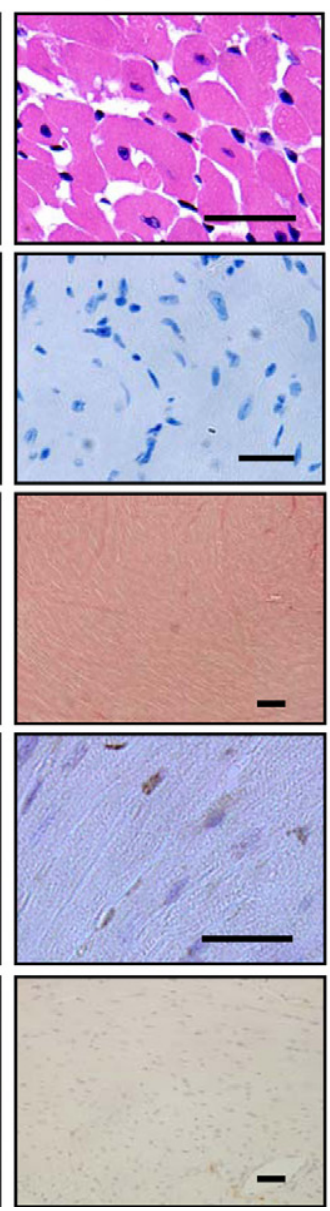

B
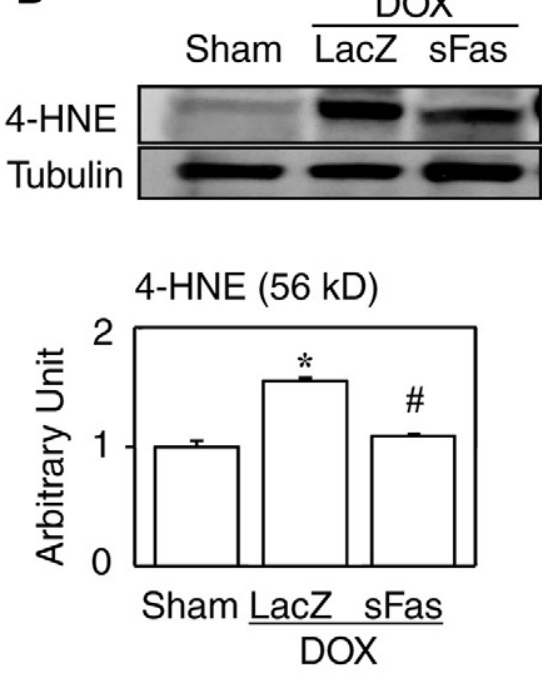

Figure 2. Effects of sFas gene delivery on cardiac histology and protein expression evaluated 2 weeks after doxorubicin injection. A: Representative photomicrographs are shown for each group. HE, hematoxylin-eosin staining; CD 45, immunohistochemical staining for CD45; Sirius Red, Sirius red staining; 8-OHdG, immunohistochemical staining for 8-OHdG; 4-HNE, immunohistochemical staining for 4-HNE. The arrow in CD 45 points to the immunopositive cell. Scale bars $=20 \mu \mathrm{m}$. B: Western blot for 4 -HNE with its densitometric analysis. ${ }^{*} P<0.05$ versus the sham group; ${ }^{*} P<0.05$ versus the doxorubicin-treated group with $\mathrm{LacZ}$ gene transfer.

\section{Apoptosis in Hearts Showing Acute Doxorubicin Cardiotoxicity}

Cardiac expression of both Fas and Fas ligand were found to be up-regulated by treatment with doxorubicin, and this effect was reversed by sFas gene therapy (Figure 4A). The TUNEL-positive cardiomyocytes and nonmyocytes were observed in each group, though in rare instances (Figure 4B). The prevalence of TUNEL-positivity in cardiomyocytes were significantly greater in the groups treated with doxorubicin, irrespective of whether the mice also received sFas gene, and sFas treatment had no significant effect on the prevalence. We failed to detect the ladder pattern of fragmented DNA characteristic of apoptosis in any groups (data not shown). Moreover, we detected no cleaved (activated) caspase-3 or caspase-8 in any of the groups, and the levels of both procaspase- 8 and -3 were unchanged between the groups (Figure 4C). Levels of two apoptosis-regulating proteins, $\mathrm{Bcl}-2$ and Bax, were not affected either by doxorubicin or the gene therapy (Figure 4D).

Electron microscopy revealed degenerative changes in cardiomyocytes from doxorubicin-treated mice, including myofibrillar derangement, disruption and loss and proliferation of subcellular organelles such as mitochondria (Figure 5A). Morphometric analysis at the electron microscopic level revealed that the \%volume comprised of myofibrils in a cardiomyocyte cell area became significantly smaller by doxorubicin ( $43 \pm 1.2 \%$ versus $54 \pm$ $1.3 \%$ in sham, $P<0.05)$; this reduction was restored by the sFas gene therapy (52 $\pm 2.0 \%$ ) (Figure $5 \mathrm{~A})$. However, no typically apoptotic cells were observed. Thus, an antidegenerative effect, but not an anti-apoptotic effect, appears to contribute significantly to the beneficial effects of sFas gene therapy on cardiac structure and function in the present model of doxorubicin cardiotoxicity.

\section{Effects of sFas on Doxorubicin-Induced Cardiomyocyte Degeneration}

Although apoptotic features were not seen, doxorubicininduced cardiotoxicity was accompanied by severe degenerative changes to the cardiomyocytes. These changes included myofibrillar derangement and disruption with increased numbers of subcellular organelles such as mitochondria (Figure 5A), which are all consistent with previously described findings. ${ }^{15,31}$ We also noted that levels of GATA-4, a key transcriptional factor regulating expression of cardiac sarcomeric proteins, ${ }^{32,33}$ were significantly diminished in the doxorubicin-treated hearts (Figure 5B), which is also consistent with earlier 
A
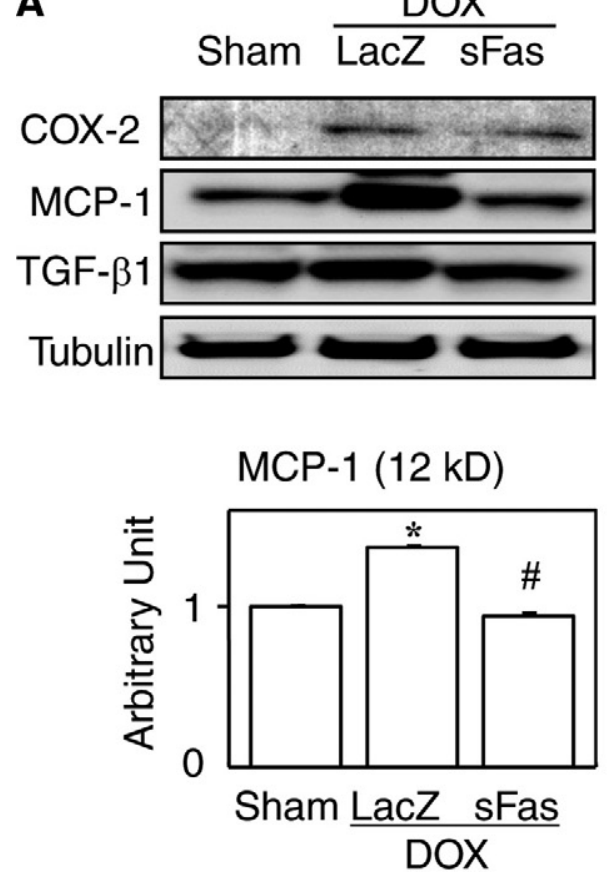

COX-2 (80 kD)
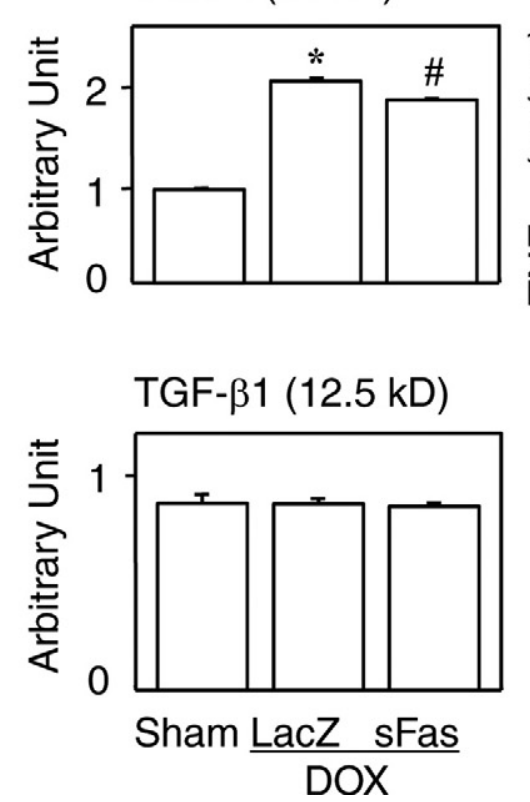

B

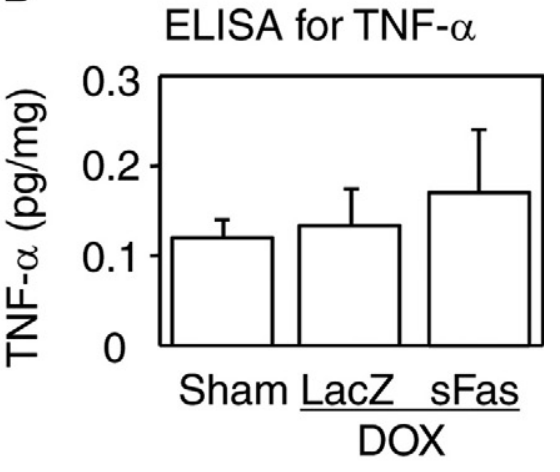

reports. ${ }^{34}$ Notably, GATA-4 expression was significantly restored by sFas treatment (Figure 5B). Likewise, the levels of two sarcomeric proteins, myosin heavy chain and troponin I, which were significantly reduced by doxorubicin, were also significantly reversed by sFas gene treatment (Figure 5B).

A recent study reported that doxorubicin treatment reduces cardiac mass via p53-dependent inhibition of mammalian target of rapamycin (mTOR), which is the major contributor to acute doxorubicin cardiotoxicity. ${ }^{35}$ Our Western blot showed a marked up-regulation of p53 in the heart by doxorubicin treatment consistent with the report $^{35}$ and also revealed a significant attenuation of p53 expression in the sFas-treated group (Figure 6A). The ubiquitination assay with immunoprecipitation revealed that doxorubicin increased polyubiquitinated myosin heavy chain and troponin I, and that the sFas treatment significantly attenuated this increase (Figure 6B). Collectively, these findings suggest that Fas signaling mediates doxorubicin-induced sarcomeric disintegration by down-regulation of GATA-4, a transcriptional factor for myosin heavy chain and troponin I, by ubiquitin-dependent degradation of those sarcomeric proteins that are in parallel with p53 expression, or by both. Although the sFas treatment exerted no protective effect against doxorubicin-induced atrophy, it appears to qualitatively improve cardiomyocyte structure and function possibly through restoration of the proportion of sarcomeric proteins in the cytoplasm.

\section{Molecular Signaling Downstream of Fas}

Our histological analysis revealed that inhibition of Fas signaling with sFas treatment attenuated doxorubicininduced myocardial inflammation and fibrosis as well as cardiomyocyte degeneration. It is known that in addition to its apoptotic signaling, Fas stimulation also evokes inflammatory signaling through activation of downstream mediators such as JNK and nuclear factor- $\kappa \mathrm{B}$ (NF$\kappa \mathrm{B}) .{ }^{16,36}$ Activation of JNK and C-Jun, as indicated by expression of the respective phosphorylated forms, was stimulated by doxorubicin, and this effect was attenuated by the sFas treatment (Figure 7A) while p38 MAPK activation was suppressed by doxorubicin, which sFas treatment did not affect (Figure 7B). The phosphorylated level of $\mid \kappa \mathrm{B}$ activation was augmented by doxorubicin, and this, too, was significantly attenuated by sFas treatment (Figure 7C), suggesting that sFas gene therapy suppresses doxorubicin-induced NF- $\kappa \mathrm{B}$ activation. Consistent with previous reports, ${ }^{15,37}$ activity of ERK was suppressed by doxorubicin and interestingly, this was restored by sFas treatment (Figure 7D).

\section{Discussion}

\section{Fas Signal Inhibition and Apoptosis in Acute Doxorubicin Cardiotoxicity}

The present study has shown that inhibition of Fas signaling significantly attenuates progression of acute doxorubicin cardiotoxicity. Nakamura et al previously used a neutralizing antibody against Fas ligand to demonstrate the beneficial effect of Fas inhibition in doxorubicin cardiotoxicity. ${ }^{6}$ We have now confirmed and extended those findings by demonstrating for the first time the efficacy of anti-Fas gene therapy in the treatment of acute doxorubicin cardiotoxicity. More important, however, may be the difference in the phenotypes of the affected hearts in the two studies. In their model, Nakamura et al noted aug- 
A
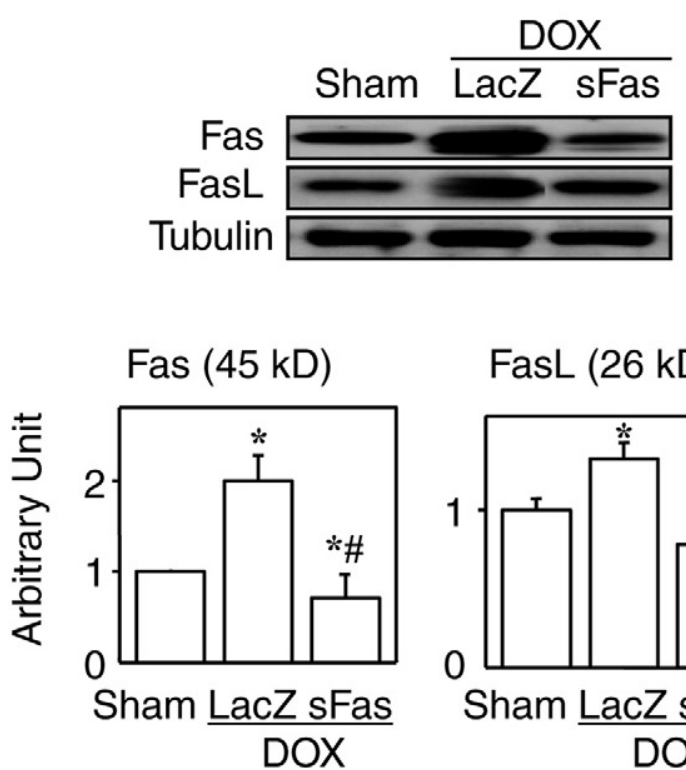

FasL (26 kD)

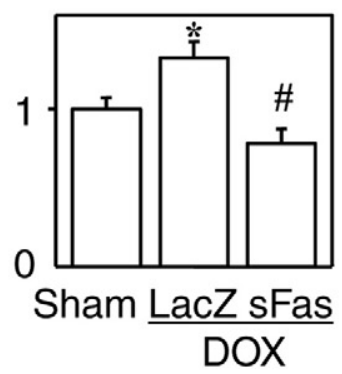

B

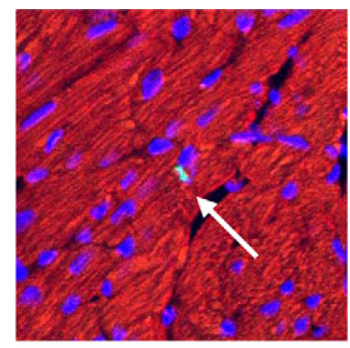

\%TUNEL in cardiomyocytes

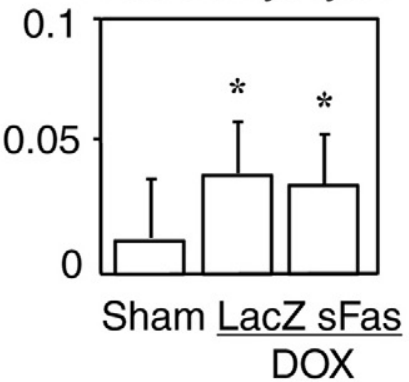

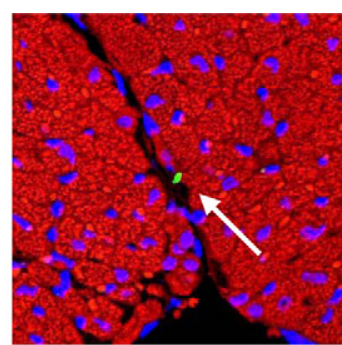

\%TUNEL in nonmyocytes

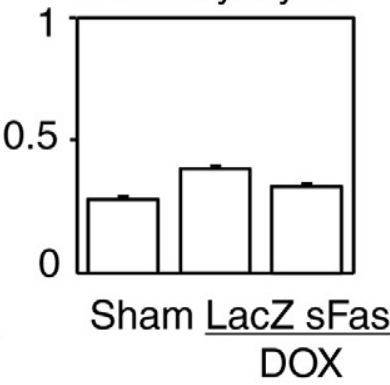

C

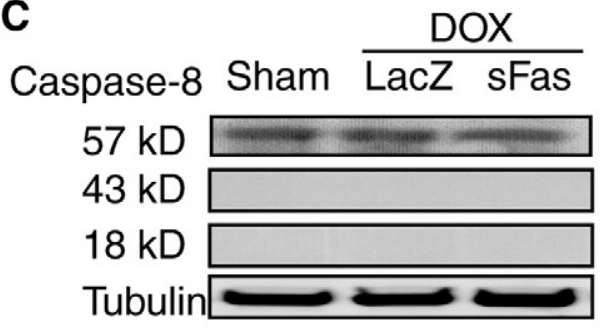

DOX

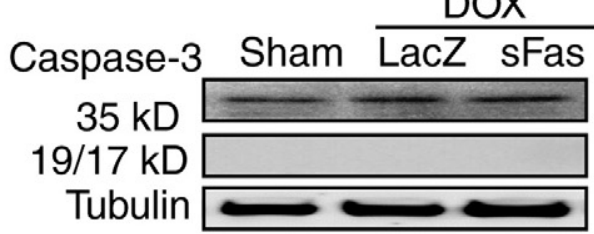

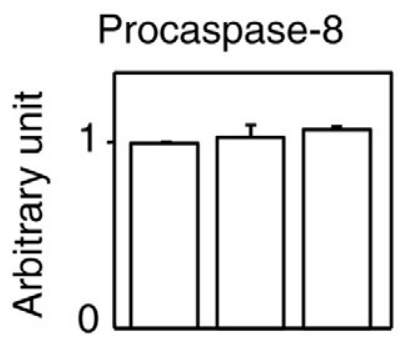

Procaspase-3

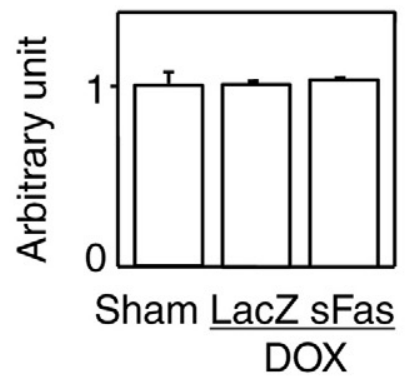

Figure 4. Effects of sFas gene delivery on expression of Fas, Fas ligand and apoptosis-related mediators in acute doxorubicin cardiotoxicity. A: Western blots for Fas and Fas ligand. B: Double immunofluorescence for TUNEL (green) and myoglobin (red) to separately evaluate TUNEL positivity for cardiomyocytes and nonmyocytes. Arrows point to TUNEL-positive cells. The left panel shows a TUNEL-positive cardiomyocyte while the right panel does a TUNEL-positive nonmyocyte. Scale bars $=10 \mu \mathrm{m}$. C: Western blots for caspase- 8 and -3 and their uncleaved (pro-) forms. Densitometries of their cleaved (activated) forms are not shown because they were undetected. D: Western blots for Bcl-2 and Bax and their densitometric analyses. ${ }^{*} P<0.05$ versus the sham group; ${ }^{*} P<0.05$ versus the doxorubicin-treated group with LacZ gene transfer.

D

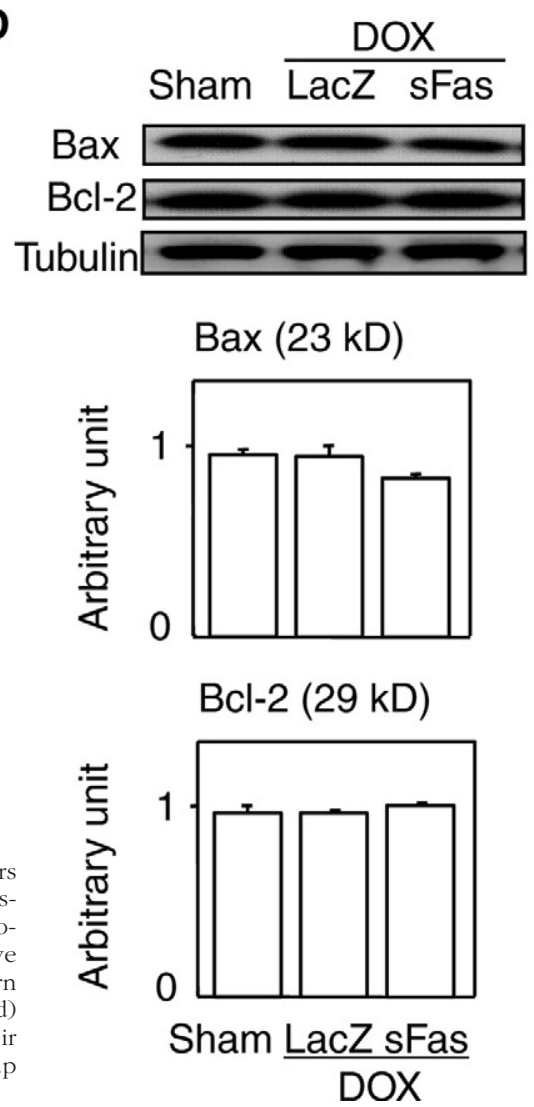

mented cardiac apoptosis (indicated by TUNEL and DNA ladder) that was significantly suppressed by Fas signal inhibition. ${ }^{6}$ By contrast, we found that inhibiting Fas signaling had no effect on the prevalence of TUNEL positivity, activation of caspase- 8 and -3 , or expression of apoptosis-related proteins Bcl-2 and Bax. The discrep- ancy in apoptosis between two studies may be most likely explained by the fact that Nakamura et al did not see apoptotic bodies until week 9 of doxorubicin treatment. ${ }^{6}$ That is, different from the study by Nakamura et al using chronic model, the current study is basically a model of acute doxorubicin cardiotoxicity. It is known 


\section{A}
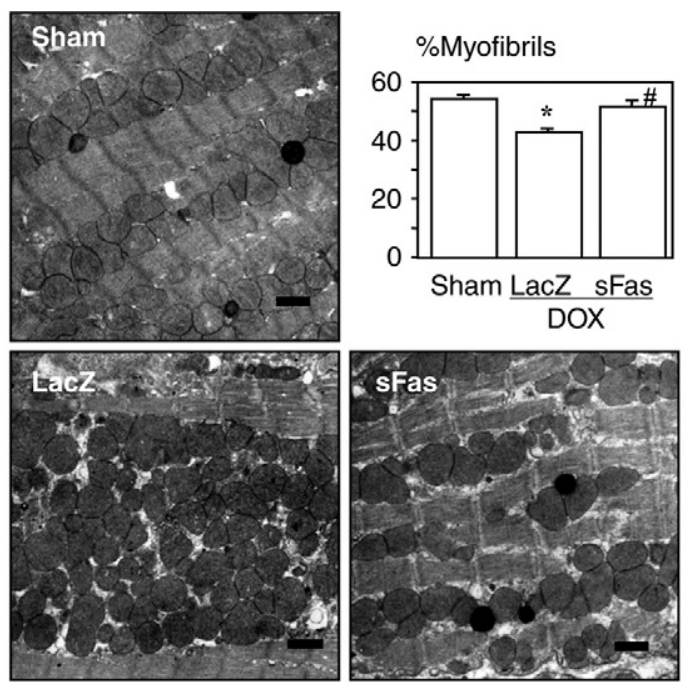

B
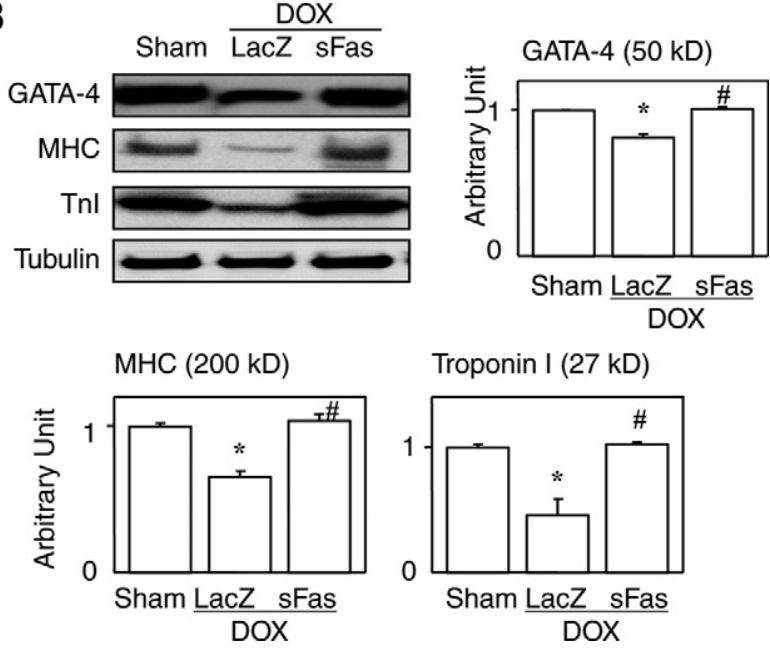

Troponin I (27 kD)

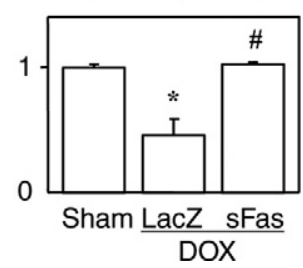

Figure 5. Effects of sFas gene delivery on cardiomyocyte ultrastructure and expression of GATA-4 and sarcomeric proteins in doxorubicin cardiotoxicity. A: Electron microphotographs. Doxorubicin treatment induced marked degenerative changes, and the damage was significantly attenuated by sFas gene delivery. Scale bars $=1 \mu \mathrm{m}$. Graph showing the percent volume comprised of myofibrils assessed by ultrastructural morphometry. ${ }^{*} P<0.05$ versus the sham group; ${ }^{\#} P<0.05$ versus the doxorubicin-treated group with LacZ gene transfer. B: Western blots for GATA-4, MHC, and troponin I. ${ }^{*} P<$ 0.05 versus the sham group; ${ }^{*} P<0.05$ versus the doxorubicin-treated group with LacZ gene transfer.

clinically that doxorubicin occasionally produces an acute cardiotoxicity while the drug causes a chronic cardiomyopathy when given repeatedly. ${ }^{1-4}$ Acute injuries occur immediately after treatment and may cause transient arrhythmia, pericarditis, myocarditis, and acute failure of the left ventricle. Chronic effects depend on the cumulative dose and result in dilated cardiomyopathylike congestive heart failure. The relevance and relationship of the findings of acute effects of doxorubicin involving non-apoptotic pathways induced by Fas signaling to chronic effects of Fas signaling to apoptosis in chronic doxorubicin cardiomyopathy is unclear. Therefore, apoptosis may be a phenomenon specifically related to chronic treatment and cardiomyopathy, but not to the relatively short-term (2 weeks) toxicity of doxorubicin like the present study.

\section{Fas Signaling Inhibition Attenuates \\ Inflammation, Fibrosis and Oxidative Damage in Acute Doxorubicin Cardiotoxicity}

The interaction of Fas and Fas ligand activates a wellknown pathway via which apoptotic signals are transduced in a variety of cell types. ${ }^{5}$ However, recent studies have shown that Fas signaling also mediates a number of biological effects unrelated to apoptosis, ${ }^{36}$ including induction of inflammation and fibrosis, ${ }^{16}$ generation of reactive oxygen species, ${ }^{17}$ acceleration of proliferation/differentiation, ${ }^{18}$ and induction of hypertrophy. ${ }^{19}$ Consistent with those findings, transgenic mice overexpressing Fas ligand in their hearts showed inflammation and fibrosis but not apoptosis, while development of cardiac hypertrophy induced by pressure overload was shown to be Fas signal-dependent. ${ }^{20}$ In the present study, inhibition of Fas signaling attenuated the myocardial inflammation and fibrosis characteristic of doxorubicin cardiotoxicity. This was accompanied by suppression of the activities of $\mathrm{C}-\mathrm{Jun}$ and NF- $\kappa \mathrm{B}$ (two inflammation-related transcription factors) and by down-regulation of cyclooxygenase-2 and MCP-1 (two inflammatory mediators), all of which were activated or augmented in hearts affected by doxorubicin. Although earlier studies reported TNF- $\alpha$ and TGF- $\beta 1$ to be potent stimulators of inflammation and fibrosis in the failing heart, ${ }^{38,39}$ their involvement in doxorubicin-induced cardiotoxicity was challenged in the recent reports. ${ }^{15,37}$ Consistent with the latter, we found no significant doxorubicin- or sFas-induced changes in the expression of TNF- $\alpha$ and TGF- $\beta 1$ despite augmented infiltration of inflammatory cells in the doxorubicin-treated hearts, which are the major source of the cytokines. The discrepancy may be partly explained by the action of doxorubicin that directly down-regulates transcription of TNF- $\alpha$ as previously reported. ${ }^{37}$ Effect of doxorubicin on TGF- $\beta 1$, on the other hand, should be elucidated in future. In addition, the diminished production of $8-\mathrm{OHdG}$ (a marker of oxidative DNA damage) and 4-HNE (a marker of oxidative damage of plasma membrane) indicates that inhibition of Fas signaling attenuates doxorubicin-induced oxidative damage to the heart.

\section{Attenuation of Cardiomyocyte Degeneration by Fas Signaling Inhibition in Acute Doxorubicin Cardiotoxicity}

Interestingly, we could not confirm the hypertrophic effect of Fas in our present model. In contrast to the compensatory cardiomyocyte hypertrophy seen in response to pressure overload, ${ }^{20}$ doxorubicin exerted an atrophic effect on cardiomyocytes that was unaffected by Fas inhibition with sFas treatment. Nonetheless, Fas inhibition did attenuate the degenerative changes to cardiomyocytes. Cardiomyocytes affected by doxorubicin cardiotoxicity show severe degenerative changes at the subcellular level, including myofibrillar derangement, disruption and loss and proliferation of subcellular organelles such as mitochondria. ${ }^{15,31}$ Such myofibrillar degeneration was re- 
A

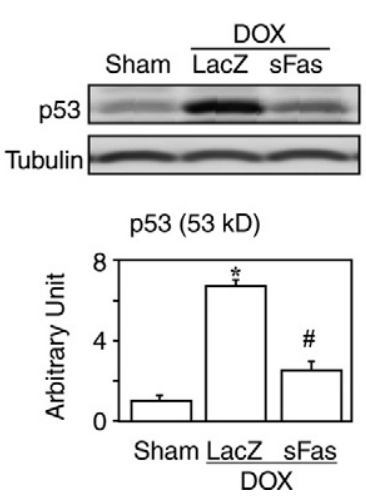

B

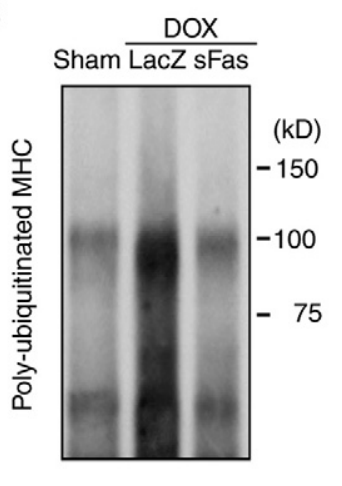

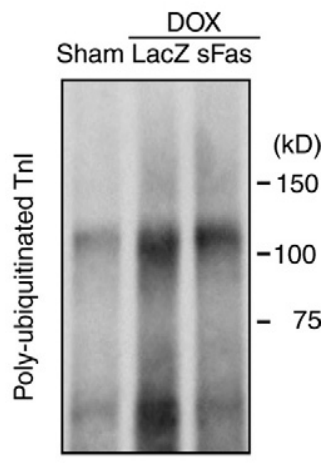

(kD)

Figure 6. Effects of sFas gene delivery on expression of $\mathrm{p} 53$ and ubiquitination of sarcomeric proteins in acute doxorubicin cardiotoxicity. A: Western blots for $\mathrm{p} 53 .{ }^{*} P<0.05$ versus the sham group ${ }^{*} P<0.05$ versus the doxorubicin-treated group with LacZ gene transfer. B: Immunoprecipitation and Western blots for polyubiquitinated myosin heavy chain (MHC) and troponin I (TnI) portedly associated with doxorubicin-induced down-regulation of GATA-4; Kim et $\mathrm{al}^{40}$ reported doxorubicin down-regulates GATA-4 expression at the gene transcriptional level and we and others, ${ }^{15,34}$ and the present study, too, confirmed the doxorubicin-induced decrease in protein expression of GATA-4. Because GATA-4 is a key transcriptional factor regulating cardiac expression of sarcomeric proteins (eg, myosin heavy chain and troponin I), ${ }^{32,33}$ it seems plausible that its down-regulation underlies the observed sarcomeric disintegration. Indeed, we not only confirmed that there was a significant reduction in GATA-4 levels in our present model, but we also noted that this reduction was significantly reversed by Fas inhibition, and that expression of myosin heavy chain and troponin I changed in accordance with the GATA-4 level. However, decrease in GATA-4 expression by doxorubicin was indeed significant but only approximately $20 \%$ in the present study, which may not be sufficient to hamper synthesis of sarcomeric proteins. A recent study reported that doxorubicin treatment mediates p53-dependent inhibition of mTOR ${ }^{35}$ mTOR is a serine/threonine protein kinase that regulates protein translation and cell growth. ${ }^{41}$ In the present study, we found that Fas inhibition significantly attenuates doxoru-
A

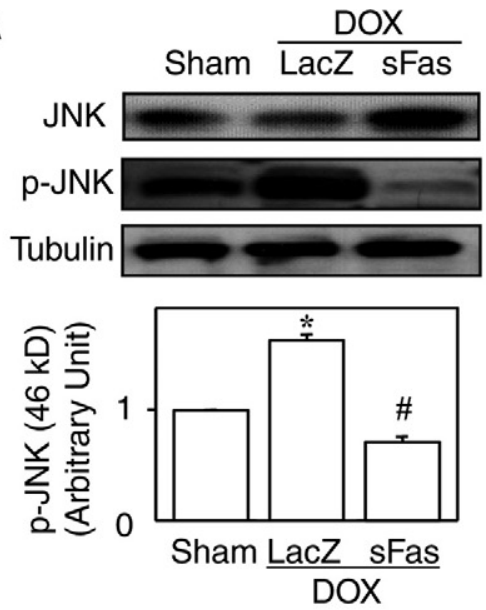

B
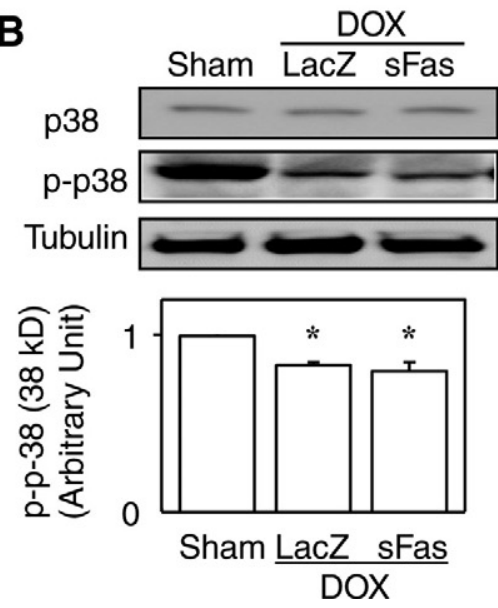

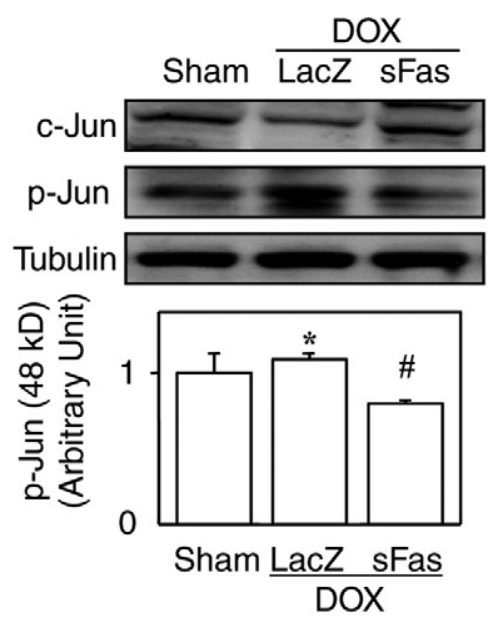

Figure 7. Effects of sFas gene delivery on myocardial expression of JNK, c-Jun, ERK, p-38 MAPK, and $\mathrm{I} \kappa \mathrm{B}$ and of their respective phosphorylated forms in doxorubicin cardiotoxicity. Western blots for JNK, p-JNK, c-Jun, and p-Jun (A); ERK and p-ERK (B); p38 and $\mathrm{p}-\mathrm{p} 38(\mathbf{C})$; and $\mathrm{I} \kappa \mathrm{B}$ and $\mathrm{p}-\mathrm{I} \kappa \mathrm{B}(\mathbf{D})$ with the densitometric analyses. ${ }^{*} P<0.05$ versus the sham group; ${ }^{*} P<0.05$ versus the doxorubicin-treated group with LacZ gene transfer.

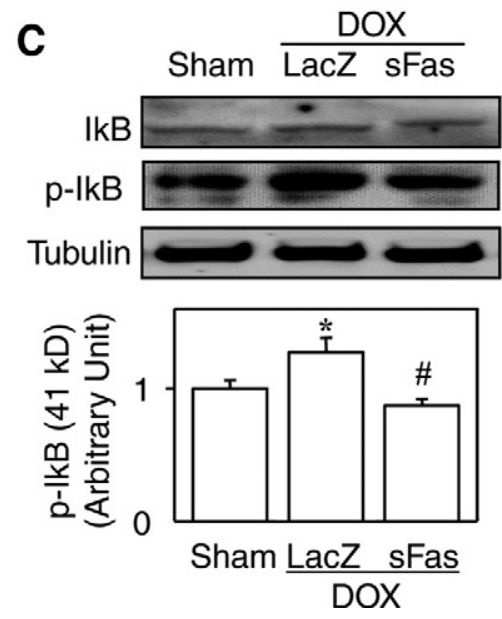

D
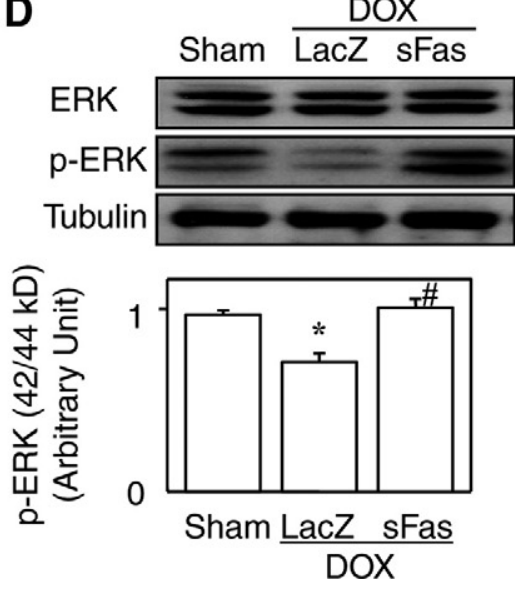
bicin-induced overexpression of p53. Since molecular pathways that inhibit protein synthesis in doxorubicin cardiotoxicity seem very complicated as discussed here, further studies are warranted to elucidate the whole picture of them.

Not only protein synthesis but also protein degradation is an important regulator of sarcomeric protein volume. For example, activation of the ubiquitin-proteasome system has been reported in doxorubicin-treated cardiomyocytes. ${ }^{42}$ In the present study, we found that doxorubicin increased ubiquitination of sarcomeric proteins (ie, myosin heavy chain and troponin I) and that the increased ubiquitination was reversed by Fas inhibition. In addition, doxorubicin was also reported to badly affect actin assembly. ${ }^{43}$ Collectively, we suggest that improvement of sarcomeric integrity by the sFas gene therapy is, at least in part, attributable to decreased GATA-4-mediated synthesis, increased degradation through ubiquitination, or both in the present acute doxorubicin cardiotoxicity model.

One would expect that restoration of sarcomeric proteins by Fas inhibition should return the cardiomyocyte size to normal. But, Fas inhibition did not affect doxorubicin-induced atrophy of cardiomyocytes. On the other hand, Fas inhibition made the proportion of sarcomeres within the cytoplasm return to normal as shown by our electron microscopic morphometry. These indicate that Fas inhibition made the proliferated nonsarcomeric constituents (eg, mitochondria) be replaced with sarcomeres to bring about a qualitative improvement of the cardiomyocytes. Also, the heart weight reduction was not affected by Fas inhibition. If the heart weight returned to normal in the sFas-treated group, the heart to body weight ratio should, curiously enough, have been significantly greater than that of the sham group because the body weight in the sFas-treated group was markedly diminished by doxorubicin. Thus, the heart weight in the sFas-treated group might have not needed to return normal as far as cardiac function was actually restored although our data suggest that mass of sarcomeres is indeed increased by Fas inhibition.

\section{Molecular Signaling in Acute Doxorubicin Cardiotoxicity Affected by Fas Inhibition}

In the present study, we found that the Fas inhibition with sFas treatment significantly affected several transcriptional factors of which expression or activation was altered by doxorubicin. p53 is one of the most extensively characterized tumor suppressor proteins and is a master regulator with pleiotropic effects on metabolism, antioxidant defense, genomic stability, senescence and cell death. ${ }^{44}$ It is well known that doxorubicin-induced p53 up-regulates Fas. ${ }^{45}$ Fas signals include JNK and NF- $\kappa$ B activation and reactive oxygen species generation. ${ }^{17}$ These activated signals subsequently evoke COX-2 and MCP-1-involved inflammation and also augment oxidative stress, both of which may again stimulate p53. The sFas gene therapy might have interrupted such a vicious feedback loop.
The effect of doxorubicin on ERK/MAPK activation has been studied previously, but the results appear to be conflicting. However, an overall consensus may be that ERK is activated during earlier phase (hours to 5 days) but is inactivated during later phase (2 to 3 weeks) after treatment with doxorubicin. ${ }^{15,37,46}$ Activity of GATA-4 transcription factor is subjected to regulation not only at the expression level but also through posttranscriptional modification of GATA-4 proteins. ${ }^{47}$ For instance, Liang et $\mathrm{al}^{48}$ reported that activated ERK ( $p$-ERK) phosphorylates GATA-4 to enhance its DNA binding and transcriptional activation. Another study using isolated rat heart subjected to excessive LV wall stress (induced by balloon inflation) showed an involvement of MAPK (p38 and ERKs) in activation of GATA-4 binding to DNA. ${ }^{49}$

In addition, p53 and protein degradation through the ubiquitin-proteasome system interact each other. ${ }^{50,51}$ Activated ERK again negatively regulates ubiquitin-proteasome system as well as autophagy to inhibit protein degradation. ${ }^{52,53}$ Collectively, we speculate that sFas exerts its cardioprotective effects via inhibition of Fas signals that evoke inflammation, fibrosis, and reactive oxygen species production which reproduce oxidative stress to activate p53 and inactivate ERK; diminished ERK decelerates GATA-4-dependent sarcomeric protein synthesis and promotes ubiquitin-dependent sarcomeric protein degradation while increased p53 not only activates Fas signaling but also promotes ubiquitin-dependent sarcomeric protein degradation. That said, it remains unknown how Fas signaling affects GATA-4 expression and ERK activation and whether the inflammation and cardiomyocyte degeneration are associated with one another. Further study will be needed to fully clarify the extraapoptotic effects of Fas signaling in the heart.

\section{Conclusion}

In conclusion, we found that sFas gene therapy prevents the progression of doxorubicin-induced acute cardiotoxicity, accompanying attenuation of the cardiomyocyte degeneration, inflammation and oxidative damage caused by Fas signaling. These findings not only provide novel mechanistic insight into the pathogenesis of acute doxorubicin cardiotoxicity but also suggest that anti-Fas gene therapy is a potentially useful approach to preventing or ameliorating acute doxorubicin cardiotoxicity. However, safety of anti-Fas strategies or a virus-mediated gene therapy has not been confirmed in humans. These issues should be resolved before clinical application of the antiFas gene therapy.

\section{Acknowledgment}

We thank Hatsue Ohshika (Gifu University Graduate School of Medicine) for technical assistance.

\section{References}

1. Olson RD, Mushlin P: Doxorubicin cardiotoxicity: analysis of prevailing hypotheses. FASEB J 1990, 4:3076-3086 
2. Shan K, Lincoff AM, Young JB: Anthracycline-induced cardiotoxicity. Ann Intern Med 1996, 125:47-58

3. Singal PK, lliskovic N: Doxorubicin-induced cardiomyopathy. N Engl J Med 1998, 339:900-905

4. Minotti G, Menna P, Salvatorelli E, Cairo G, Gianni L: Anthracyclines: molecular advances and pharmacologic developments in antitumor activity and cardiotoxicity. Pharmacol Rev 2004, 56:185-229

5. Nagata S: Apoptosis by death factor. Cell 1997, 8:355-365

6. Nakamura T, Ueda Y, Juan Y, Katsuda S, Takahashi H, Koh E: Fas-mediated apoptosis in adriamycin-induced cardiomyopathy in rats: in vivo study. Circulation 2000, 102:572-578

7. Yamaoka M, Yamaguchi S, Suzuki T, Okuyama M, Nitobe J, Nakamura $\mathrm{N}$, Mitsui $\mathrm{Y}$, Tomoike H: Apoptosis in rat cardiac myocytes induced by Fas ligand: priming for Fas-mediated apoptosis with doxorubicin. J Mol Cell Cardiol 2000, 32:881-889

8. Kalivendi SV, Konorev EA, Cunningham S, Vanamala SK, Kaji EH, Joseph J, Kalyanaraman B: Doxorubicin activates nuclear factor of activated T-lymphocytes and Fas ligand transcription: role of mitochondrial reactive oxygen species and calcium. Biochem J 2005, 389:527-539

9. Hayakawa K, Takemura G, Koda M, Kawase Y, Maruyama R, Li Y, Minatoguchi S, Fujiwara T, Fujiwara H: Sensitivity to apoptosis signal, clearance rate, and ultrastructure of fas ligand-induced apoptosis in in vivo adult cardiac cells. Circulation 2002, 105:3039-3045

10. Wollert KC, Heineke J, Westermann J, Ludde M, Fiedler B, Zierhut W, Laurent D, Bauer MK, Schulze-Osthoff K, Drexler H: The cardiac Fas (APO-1/CD95) Receptor/Fas ligand system : relation to diastolic wall stress in volume-overload hypertrophy in vivo and activation of the transcription factor AP-1 in cardiac myocytes. Circulation 2000 101:1172-1178

11. Jeremias I, Stahnke K, Debatin KM: CD95/Apo-1/Fas: independent cell death induced by doxorubicin in normal cultured cardiomyocytes. Cancer Immunol Immunother 2005, 54:655-662

12. Kotamraju S, Konorev EA, Joseph J, Kalyanaraman B: Doxorubicininduced apoptosis in endothelial cells and cardiomyocytes is ameliorated by nitrone spin traps and ebselen. Role of reactive oxygen and nitrogen species J Biol Chem 2000, 275:33585-33592

13. Wang L, Ma W, Markovich R, Chen JW, Wang PH: Regulation of cardiomyocyte apoptotic signaling by insulin-like growth factor I. Circ Res 1998, 83:516-522

14. Zhang J, Clark JR Jr, Herman EH, Ferrans VJ: Doxorubicin-induced apoptosis in spontaneously hypertensive rats: differential effects in heart, kidney and intestine, and inhibition by ICRF-187. J Mol Cell Cardiol 1996, 28:1931-1943

15. Li L, Takemura G, Li Y, Miyata S, Esaki M, Okada H, Kanamori H, Khai NC, Maruyama R, Ogino A, Minatoguchi S, Fujiwara T, Fujiwara H: Preventive effect of erythropoietin on cardiac dysfunction in doxorubicin-induced cardiomyopathy. Circulation 2006, 113:535-543

16. Miwa K, Asano M, Horai R, Iwakura Y, Nagata S, Suda T: Caspase 1-independent IL-1beta release and inflammation induced by the apoptosis inducer Fas ligand. Nat Med 1998, 4:1287-1292

17. Devadas S, Hinshaw JA, Zaritskaya L, Williams MS: Fas-stimulated generation of reactive oxygen species or exogenous oxidative stress sensitize cells to Fas-mediated apoptosis. Free Radic Biol Med 2003, 35:648-661

18. Zhang J, Cado D, Chen A, Kabra NH, Winoto A: Fas-mediated apoptosis and activation-induced T-cell proliferation are defective in mice lacking FADD/Mort1. Nature 1998, 392:296-300

19. Nelson DP, Setser E, Hall DG, Schwartz SM, Hewitt T, Klevitsky R, Osinska H, Bellgrau D, Duke RC, Robbins J: Proinflammatory consequences of transgenic fas ligand expression in the heart. J Clin Invest 2000, 105:1199-1208

20. Badorff C, Ruetten H, Mueller S, Stahmer M, Gehring D, Jung F, Ihling C, Zeiher AM, Dimmeler S: Fas receptor signaling inhibits glycogen synthase kinase 3 beta and induces cardiac hypertrophy following pressure overload. J Clin Invest 2002, 109:373-381

21. Mizuguchi H, Kay AM: A simple method for constructing E1- and E1/E4-deleted recombinant adenoviral vectors. Human Gen Ther 1999, 10:2013-2017

22. Suda T, Nagata S: Purification and characterization of the Fas-ligand that induces apoptosis. J Exp Med 1994, 179:873-879

23. Chen SH, Chen XH, Wang Y, Kosai K, Finegold MJ, Rich SS, Woo SL: Combination gene therapy for liver metastasis of colon carcinoma in vivo. Proc Natl Acad Sci USA 1995, 92:2577-2581
24. Li Y, Takemura G, Kosai K, Takahashi T, Okada H, Miyata S, Yuge K, Nagano S, Esaki M, Khai NC, Goto K, Mikami A, Maruyama R, Minatoguchi S, Fujiwara T, Fujiwara H: Critical roles for the Fas/Fas ligand system in postinfarction ventricular remodeling and heart failure. Circ Res 2004, 95:627-636

25. Ohno M, Takemura G, Ohno A, Misao J, Hayakawa Y, Minatoguchi S, Fujiwara T, Fujiwara H: "Apoptotic" myocytes in infarct area in rabbit hearts may be oncotic myocytes with DNA fragmentation: analysis by immunogold electron microscopy combined with In situ nick endlabeling. Circulation 1998, 98:1422-1430

26. Anversa P, Loud AV, Vitali-Mazza L: Morphometry and autoradiography of early hypertrophic changes in the ventricular myocardium of adult rat: an electron microscopic study. Lab Invest 1976, 35:475-483

27. Nishigaki K, Minatoguchi S, Seishima M, Asano K, Noda T, Yasuda N, Sano H, Kumada H, Takemura M, Noma A, Tanaka T, Watanabe S, Fujiwara H: Plasma Fas ligand, an inducer of apoptosis, and plasma soluble Fas, an inhibitor of apoptosis, in patients with chronic congestive heart failure. J Am Coll Cardiol 1997, 29:1214-1220

28. Toyokuni S, Tanaka T, Hattori Y, Nishiyama Y, Yoshida A, Uchida K Hirai H, Ochi H, Osawa T: Quantitative immunohistochemical determination of 8-hydroxy-2'-deoxyguanosine by a monoclonal antibody N45.1: its application to ferric nitrilotriacetate-induced renal carcinogenesis model. Lab Invest 1997, 76:365-374

29. Toyokuni S, Uchida K, Okamoto K, Hattori-Nakakuki Y, Hiai H, Stadtman ER: Formation of 4-hydroxy-2-nonenal-modified proteins in the renal proximal tubules of rats treated with a renal carcinogen, ferric nitrilotriacetate. Proc Natl Acad Sci USA 1994, 91:2616-2620

30. Esterbauer H, Benedetti A, Lang J, Fulceri R, Fauler G, Comporti $\mathrm{M}$ : Studies on the mechanism of formation of 4-hydroxynonenal during microsomal lipid peroxidation. Biochim Biophys Acta 1986, 876:154-166

31. Rosenoff SH, Olson HM, Young DM, Bostick F, Young RC: Adriamycin-induced cardiac damage in the mouse: a small-animal model of cardiotoxicity. J Natl Cancer Inst 1975, 55:191-194

32. Molkentin JD, Kalvakolanu DV, Markham BE: Transcription factor GATA-4 regulates cardiac muscle-specific expression of the alphamyosin heavy-chain gene. Mol Cell Biol 1994, 14:4947-4957

33. Murphy AM, Thompson WR, Peng LF, Jones $L$ 2nd: Regulation of the rat cardiac troponin I gene by the transcription factor GATA-4. Biochem J 1997, 322:393-401

34. Aries A, Paradis P, Lefebvre C, Schwartz RJ, Nemer M: Essential role of GATA-4 in cell survival and drug-induced cardiotoxicity. Proc Natl Acad Sci USA 2004, 101:6975-6980

35. Zhu W, Soonpaa MH, Chen H, Shen W, Payne RM, Liechty EA, Caldwell RL, Shou W, Field LJ: Acute doxorubicin cardiotoxicity is associated with p53-induced inhibition of the mammalian target of rapamycin pathway. Circulation 2009, 119:99-106

36. Wajant H, Pfizenmaier K, Scheurich P: Non-apoptotic Fas signaling Cytokine Growth Factor Rev 2003, 14:53-66

37. Lou H, Danelisen I, Singal PK: Cytokines are not upregulated in adriamycin-induced cardiomyopathy and heart failure. J Mol Cell Cardiol 2004, 36:683-690

38. Bryant D, Becker L, Richardson J, Shelton J, Franco F, Peshock R Thompson M, Giroir B: Cardiac failure in transgenic mice with myocardial expression of tumor necrosis factor-alpha. Circulation 1998 97:1375-1381

39. Hein S, Arnon E, Kostin S, Schönburg M, Elsässer A, Polyakova V, Bauer EP, Klövekorn WP, Schaper J: Progression from compensated hypertrophy to failure in the pressure-overloaded human heart: structural deterioration and compensatory mechanisms. Circulation 2003, 107:984-991

40. Kim Y, Ma AG, Kitta K, Fitch SN, Ikeda T, Ihara $Y$, Simon AR, Evans T, Suzuki YJ: Anthracycline-induced suppression of GATA-4 transcription factor: implication in the regulation of cardiac myocyte apoptosis. Mol Pharmacol 2003, 63:368-377

41. Lee $\mathrm{CH}$, Inoki K, Guan KL: mTOR pathway as a target in tissue hypertrophy. Annu Rev Pharmacol Toxicol 2007, 47:443-467

42. Kumarapeli AR, Horak KM, Glasford JW, Li J, Chen Q, Liu J, Zheng H, Wang $X$ : A novel transgenic mouse model reveals deregulation of the ubiquitin-proteasome system in the heart by doxorubicin. FASEB $J$ 2005, 19:2051-2053

43. Colombo R, Necco A, Vailati G, Saracco B, Milzani A, Scarì G: Doxorubicin affects actin assembly in vitro. Cell Biol Int Rep 1984, 8:127-135 
44. Vousden KH, Lane DP: p53 in health and disease. Nat Rev Mol Cell Biol 2007, 8:275-283

45. Müller M, Wilder S, Bannasch D, Israeli D, Lehlbach K, Li-Weber M, Friedman SL, Galle PR, Stremmel W, Oren M, Krammer PH: p53 activates the CD95 (APO-1/Fas) gene in response to DNA damage by anticancer drugs. J Exp Med 1998, 188:2033-2045

46. Bien S, Riad A, Ritter CA, Gratz M, Olshausen F, Westermann D, Grube M, Krieg T, Ciecholewski S, Felix SB, Staudt A, Schultheiss HP, Ewert R, Völker U, Tschöpe C, Kroemer HK: The endothelin receptor blocker bosentan inhibits doxorubicin-induced cardiomyopathy. Cancer Res 2007, 67:10428-10435

47. Pikkarainen S, Tokola H, Kerkelä R, Ruskoaho H: GATA transcription factors in the developing and adult heart. Cardiovasc Res 2004, 63:196-207

48. Liang Q, Wiese RJ, Bueno OF, Dai YS, Markham BE, Molkentin JD: The transcription factor GATA4 is activated by extracellular signalregulated kinase 1- and 2-mediated phosphorylation of serine 105 in cardiomyocytes. Mol Cell Biol 2001, 21:7460-7469

49. Tenhunen O, Sármán B, Kerkelä R, Szokodi I, Papp L, Tóth $M$, Ruskoaho $\mathrm{H}$ : Mitogen-activated protein kinases p38 and ERK 1/2 mediate the wall stress-induced activation of GATA-4 binding in adult heart. J Biol Chem 2004, 279:24852-24860

50. Thompson SJ, Loftus LT, Ashley MD, Meller R: Ubiquitin-proteasome system as a modulator of cell fate. Curr Opin Pharmacol 2008, 8:90-95

51. Birks EJ, Latif N, Enesa K, Folkvang T, Luong le A, Sarathchandra P, Khan M, Ovaa H, Terracciano CM, Barton PJ, Yacoub MH, Evans PC: Elevated p53 expression is associated with dysregulation of the ubiquitin-proteasome system in dilated cardiomyopathy. Cardiovasc Res 2008, 79:472-480

52. Yamashita M, Shinnakasu R, Asou H, Kimura M, Hasegawa A, Hashimoto K, Hatano N, Ogata M, Nakayama T: Ras-ERK MAPK cascade regulates GATA3 stability and Th2 differentiation through ubiquitin-proteasome pathway. J Biol Chem 2005, 280:29409-29419

53. Corcelle E, Nebout M, Bekri S, Gauthier N, Hofman P, Poujeol P, Fénichel P, Mograbi B: Disruption of autophagy at the maturation step by the carcinogen lindane is associated with the sustained mitogenactivated protein kinase/extracellular signal-regulated kinase activity. Cancer Res 2006, 66:6861-6870 